Research Paper

\title{
Vicious circle of acute radiation toxicities and weight loss predicts poor prognosis for nasopharyngeal carcinoma patients receiving intensity modulated radiotherapy
}

\author{
Guo Li1 ${ }^{1,2,3}$, Xiong-ying Jiang 2,4 , Bo Qiu ${ }^{2,3}$, Lu-Jun Shen ${ }^{2,3}$, Chen Chen ${ }^{2,3}$, Yun-Fei Xia ${ }^{2,3 凶}$ \\ 1. Department of Radiation Oncology, Cancer Center of Guangzhou Medical University, Guangzhou, Guangdong 510095, P. R. China; \\ 2. State Key Laboratory of Oncology in South China, Guangzhou, Guangdong 510060, P. R. China; \\ 3. Department of Radiation Oncology, Sun Yat-sen University Cancer Center, Guangzhou, Guangdong 510060, P. R. China; \\ 4. Department of Interventional Radiology, Sun Yat-sen Memorial Hospital, Guangzhou, Guangdong 510120, P. R. China. \\ $\triangle$ Corresponding author: Yun-Fei Xia, 651 Dongfeng Road East, Guangzhou 510060, People's Republic of China. Tel: 86-20-87343169; Fax: 86-20-87343392; \\ Email: xiayf@sysucc.org.cn. \\ (c) Ivyspring International Publisher. This is an open access article distributed under the terms of the Creative Commons Attribution (CC BY-NC) license \\ (https://creativecommons.org/licenses/by-nc/4.0/). See http://ivyspring.com/terms for full terms and conditions.
}

Received: 2016.09.04; Accepted: 2016.12.22; Published: 2017.03.07

\begin{abstract}
Background: Weight loss during radiotherapy has been known as a negative prognostic factor for nasopharyngeal carcinoma (NPC) patients, but the factors related to weight loss during radiotherapy were not fully understood.

Methods: A total of 322 newly diagnosed NPC patients receiving intensity modulated radiotherapy (IMRT) in Sun Yat-sen University Cancer Center between June 2002 and August 2006 were enrolled. Kaplan-Meier methods and log-rank test were applied for survival analysis; a multiple regression was used to identify the factors related to weight loss during radiotherapy.

Results: The mean and median values of weight loss (\%) during radiotherapy were $6.85 \%$ and $6.70 \%$. NPC patients with critical weight loss (>5.4\%) have poorer overall survival (OS) and distant metastasis-free survival (DMFS) than the patients without critical weight loss $(p=0.002$ and 0.021 , respectively). Pre-radiotherapy weight, acute mucosal toxicity, acute pharynx and esophagus toxicity, and acute upper gastrointestinal toxicity were related to the weight loss during radiotherapy independently $(p=0.01, p<0.001, p<0.001$, and $p=0.009$, respectively).

Conclusions: Acute radiation toxicities had significant and independent impact on weight loss during radiotherapy. The vicious circle of acute radiation toxicities and weight loss had bad effect on prognosis of NPC patients.
\end{abstract}

Key words: Weight loss, Acute radiation toxicities, Prognosis, Nasopharyngeal carcinoma, Intensity modulated radiotherapy

\section{Introduction}

Nasopharyngeal carcinoma (NPC) is an epithelial malignancy distinguished from other head and neck cancers and prevalent in Southeast Asia, the Mediterranean basin, and South China [1]. In recent years, with the increased application of intensity modulated radiotherapy (IMRT), which optimizes the radiation deposition in the tumor while sparing the adjacent normal structures, the 3 year local control rates of NPC has reached above 90\% [2-6]. However, the process of IMRT will still bring miserable suffering to NPC patient. A critical weight loss is a very common symptom during IMRT. In a prospective study from northern China, $56 \%$ of 159 NPC patients had a more than $5 \%$ weight loss during radiotherapy, the median weight loss was $6.9 \mathrm{~kg}$ [7]. Weight loss, which refers to malnutrition and cancer 
cachexia, may negatively affect patients' response to treatment, sense of well-being, health-related quality of life (HRQOL), and increase the risk of infections and treatment toxicities [8-11]. In our previous studies, we had confirmed that critical weight loss during radiotherapy was a poor prognostic factor for NPC patients. Some general clinical characteristics were found to be related to weight loss during radiotherapy, such as tumor stage, pretreatment body weight, pretreatment body mass index (BMI), and karnofsky performance status (KPS) [12-14]. However, these previous analyses, taking only general clinical characteristics into consideration, had not investigated the impact of radiotherapy-induced acute radiation toxicities on weight loss. As we know, acute radiation toxicity, like mucositis, dysgeusia, xerostomia, nausea and vomiting, which may cause systemic inflammatory and feed decreased, was always been considered to be main cause of weight loss during radiotherapy [15-18]. So, in this study, through evaluating acute radiation toxicities for 322 NPC patients receiving radical IMRT, we aimed to fully investigate the potential influence factors of weight loss during radiotherapy.

\section{Patients and Methods}

\section{Study population}

The retrospective study enrolled 418 newly diagnosed NPC patients that involved curative treatment with IMRT with or without concurrent chemotherapy in Sun Yat-sen University Cancer Center between June 2002 and August 2006. The routine workup included a complete physical examination, hematologic and biochemistry profiles, fiberoptic endoscope examination of the nasopharynx, magnetic resonance imaging, or contrast-enhanced computed tomography of the head and neck to accurately evaluate the primary tumor and regional lymph nodes. Chest radiography, bone scintigraphy, and ultrasonography of the abdominal region were used to exclude distant metastases. All the patients were restaged according to the $6^{\text {th }}$ edition of Union for International Cancer Control /American Joint Committee on Cancer (UICC/AJCC).

\section{Treatment guidelines}

All patients were scanned from the vertex to the clavicles with serial 3-mm slices before radiotherapy. Inverse IMRT planning was performed using the Corvus system, version 3.0 (Peacock, Nomos, Deer Park, IL), meanwhile, a MiMi multileaf collimator (Nomos, Sewickly, PA) was used for planning and treatment. The prescribed dose was $68 \mathrm{~Gy}$ to the planning tumor volume (PTV) of the gross tumor volume(GTV), 60 Gy to the PTV of the first clinical tumor volume (CTV-1), 54 Gy to the PTV of the CTV-2, and 64-66 Gy to the PTV of the GTV for the involved cervical lymph nodes in 30-31 fractions. Chemotherapy consisted of cisplatinum (DDP) and 5-fluorouracil (5-FU). DDP $80 \sim 100 \mathrm{mg} / \mathrm{m}^{2}$ bolus injection was delivered on day 1 and 5-FU 500 1000 $\mathrm{mg} / \mathrm{m}^{2}$ was administered by 120 -hour continuous infusion daily, day 1 through day 5 for 5 days. During radiotherapy, the patients kept their regular meals. Feeding tubes were used for 5 patients who were unable to eat. Parenteral nutrition was not a routine nutritional support in this population.

\section{Measuring of weight loss during radiotherapy}

Body weight (kg, kilograms) was taken from fasting patients who were shoeless and wearing lightweight clothing. Pre-radiotherapy (RT) weight was measured within 7 days before radiotherapy, and Post-RT body weight was measured within 7 days after completion of radiotherapy. Weight loss during radiotherapy was based on the equation: (Pre-RT weight - Post-RT weight)/ Pre-RT weight $\times 100 \%$.

\section{Evaluation of acute radiation toxicities during radiotherapy}

For each NPC patient during radiotherapy, we recorded detailed radiation-induced tissue changes at least once a week into the patient's progress note. At the end of radiotherapy, an evaluation score table was used to grade the worst toxicities according to the Acute Radiation Morbidity Scoring Criteria of the Radiation Therapy Oncology Group (RTOG). The target tissues mainly included skin, mucosal, salivary gland, pharynx and esophagus, larynx, eye, ear, and upper gastrointestinal. The severity of toxicities is graded from 0-4 (0 - absence of radiation effects; 5 effects led to death) [19]. All toxicities Grade 3, 4, 5 were verified by principal investigator to ensure the reliability of the evaluation.

\section{Follow-up}

After completion of radiotherapy, patients were followed up every 3 months for the first 3 years by clinic visits, telephone, letter and so on. The intervals gradually increased from 6 months to 1 year after 3 years.

\section{Statistical analysis}

SPSS version 13.0 was used for data processing. To investigate whether weight loss (\%) had an impact on prognosis, a receiver operating characteristic (ROC) curve was used to determine the best threshold value for weight loss (\%) which would be predictive of mortality. The best threshold was the minimal distance to the ideal point $($ sensitivity $=$ specificity $=$ $100 \%$ ) on the ROC curve. It provided a criterion for 
choosing the "optimal" threshold value, the threshold value for which $\mathrm{Se}(\mathrm{c})+\mathrm{Sp}(\mathrm{c})-1$ is maximized [20], then all the patients were divided into two groups according the best threshold value. Survivial comparisons between the two groups were analyzed by Kaplan-Meier methods and log-rank test. Bivariate analyses were performed to examine the associations between weight loss and other clinical factors, and a multiple regression analysis was performed to identify the factors that were independently related to weight loss during radiotherapy. Independent influence factors of weight loss were identified by a Cox proportional hazards model. All statistical tests were two-sided, and $p<0.05$ was considered statistically significant.

\section{Results}

\section{Demographic profiles and follow-up}

96 patients were excluded from the 418 NPC patients (81 patients without acute toxicities evaluation; 15 patients without persistent follow-up). The remained 322 NPC patients were enrolled into analysis. Demographic profiles were described in Table 1.

The median follow-up was 73 months (range, 6 108 months). The 3- and 5-year overall survival (OS) rates were $88 \%$ and $84 \%$; the local recurrence free survival (LRFS) rates were 93\% and 93\%; the distant metastasis free survival (DMFS) rates were $90 \%$ and $88 \%$.

\section{Critical weight loss during radiotherapy predicts poor prognosis}

The weight loss during radiotherapy of the 322 NPC patients was showed in Figure 1. A majority (301, 93.5\%) of NPC patients had weight loss during radiotherapy. The mean value and median value of weight loss (\%) were $6.85 \%$ and $6.70 \%$, respectively. $211(65.5 \%)$ patients had $>5 \%$ weight loss, $72(22.4 \%)$ patients had $>10 \%$ weight loss.

A receiver operating characteristic (ROC) curve was used to evaluate the weight loss (\%) cut off value for mortality. The area under the ROC curve (AUC) was 0.623 (95\% CI 0.544-0.702; $p=0.004)$. The weight loss $(\%)$ cut off value was $5.4 \%$ (the sensitivity was $81.5 \%$, the specificity was $41 \%$ ). Then, patients were grouped into weight loss $\leq 5.4 \%$ group $(n=120)$ and weight loss $>5.4 \%$ group $(n=202)$. We defined weight loss $>5.4 \%$ as critical weight loss (CWL). Survival comparisons between the two groups revealed that the patients with critical weight loss had worse OS and DMFS than those patients without critical weight loss (Figure 2). The 5-year OS rates were $79 \%$ vs. 93\% $\left(X^{2}=9.933, p=0.002\right)$ (Figure $\left.2 \mathrm{~A}\right)$; and the 5-year
DMFS rates were $85 \%$ vs. $93 \%\left(\chi^{2}=5.301, p=0.021\right)$ (Figure 2B).

Table 1. Demographic profiles of the 322 nasopharyngeal carcinoma patients

\begin{tabular}{ll}
\hline Patient characteristics & Number of patients (\%) \\
\hline Gender & $242(75.2)$ \\
Male & $80(24.8)$ \\
Female & \\
Age & $170(52.8)$ \\
$\leq 43$ years & $152(47.2)$ \\
$>43$ years & \\
UICC Tumor Stage (2010) & $28(8.7)$ \\
I & $75(23.3)$ \\
II & $155(48.1)$ \\
III & $64(19.9)$ \\
IV & \\
Treatment & $221(68.6)$ \\
RT+CT & $101(31.4)$ \\
RT & \\
Histology type & $2(0.6)$ \\
WHO Type I & $39(12.1)$ \\
WHO Type II & $281(87.3)$ \\
WHO Type III & \\
Status & $268(83.2)$ \\
Alive & $54(16.8)$ \\
Dead & \\
Recurrence & $22(6.8)$ \\
Yes & $300(93.2)$ \\
No & \\
Metastasis & $38(11.8)$ \\
Yes & $284(88.2)$ \\
No &
\end{tabular}

Abbreviations: UICC = Union for International Cancer Control; RT = radiotherapy; $\mathrm{CT}=$ chemotherapy $; \mathrm{WHO}=$ World Health Organization histological classification ( Type I - Keratinizing squamous cell carcinoma; Type II - Differentiated non-keratinizing carcinoma; Type III - Undifferentiated non-keratinizing carcinoma).

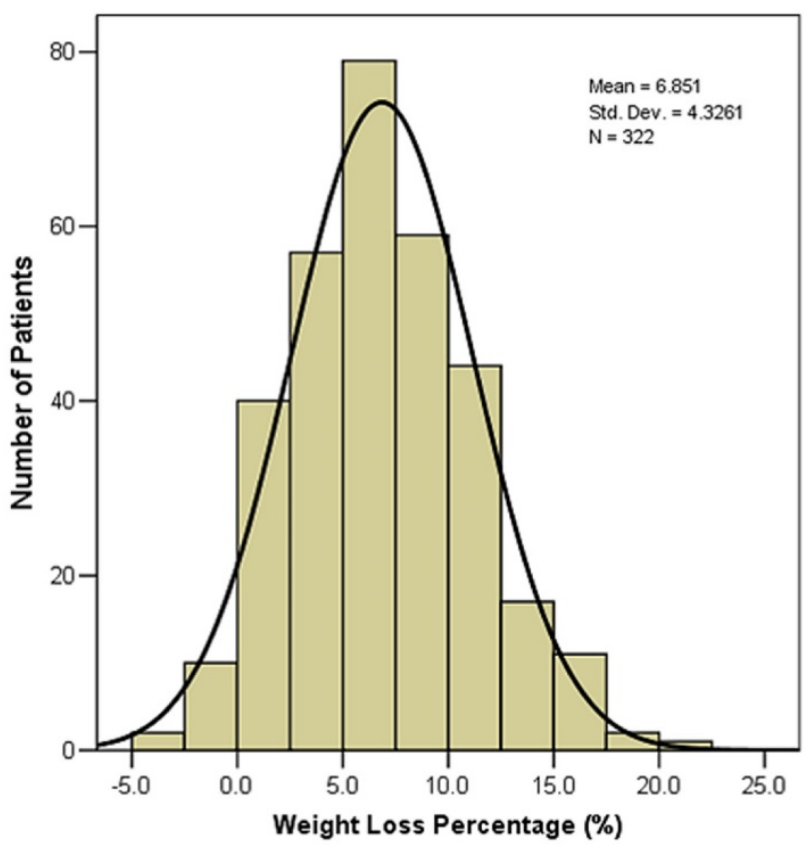

Figure 1. Weight loss (\%) during radiotherapy of the 322 nasopharyngeal carcinoma patients 


\section{The factors associated with weight loss during radiotherapy}

Among the baseline clinical characteristics, tumor stage $(p<0.001)$, chemotherapy $(p<0.001)$, pre-RT weight $(p=0.021)$, and pretreatment albumin level $(p=0.045)$ were significantly associated with weight loss during radiotherapy. (Table 2)

The acute radiation toxicities evaluation of the 322 NPC patients was showed in Figure 3. The acute radiation toxicities often began at the $2^{\text {nd }}$ week of the radiotherapy, and the worst toxicities always occurred in the $4^{\text {th }}$ to the $5^{\text {th }}$ week of the radiotherapy. The most frequent acute radiation toxicities appeared in skin, mucosal, and salivary gland. Only 3 patients

A

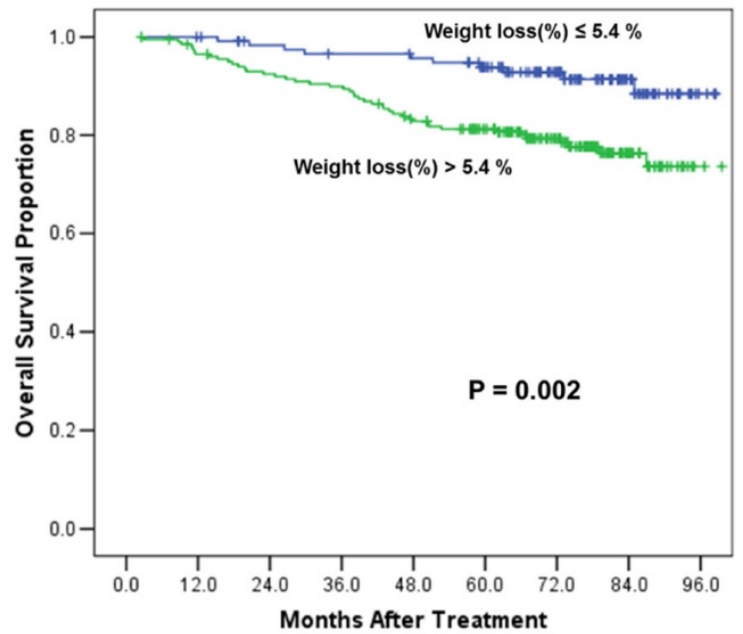

developed Grade 4 toxicity (2 developed ulcerations in mucosal; 1 developed ulceration in pharynx and esophagus). In the bivariate analyses, the acute radiation toxicities in skin $(p=0.001)$, mucosal $(p<$ $0.001)$, pharynx and esophagus $(p<0.001)$, and upper gastrointestinal $(p=0.003)$ were associated with weight loss (\%) during radiotherapy. (Table 3)

Multiple linear regression analysis found that, pre-RT weight, acute mucosal toxicity, acute pharynx and esophagus toxicity, and acute upper gastrointestinal toxicity had independent impact on weight loss (\%) during radiotherapy $(p=0.01, p<$ $0.001, p<0.001$, and $p=0.009$, respectively). (Table 4)

B

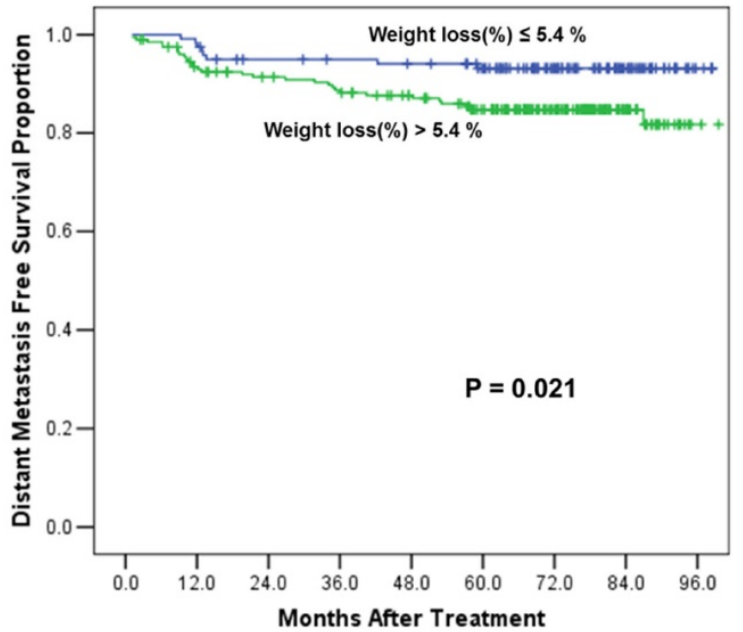

Figure 2. Overall survival and distant metastasis free survival curves comparisons between the patients with critical weight loss (>5.4\%) and patients without critical weight loss $(\leq 5.4 \%)$. (A), Comparison of overall survival curves. (B), Comparison of distant metastasis free survival curves

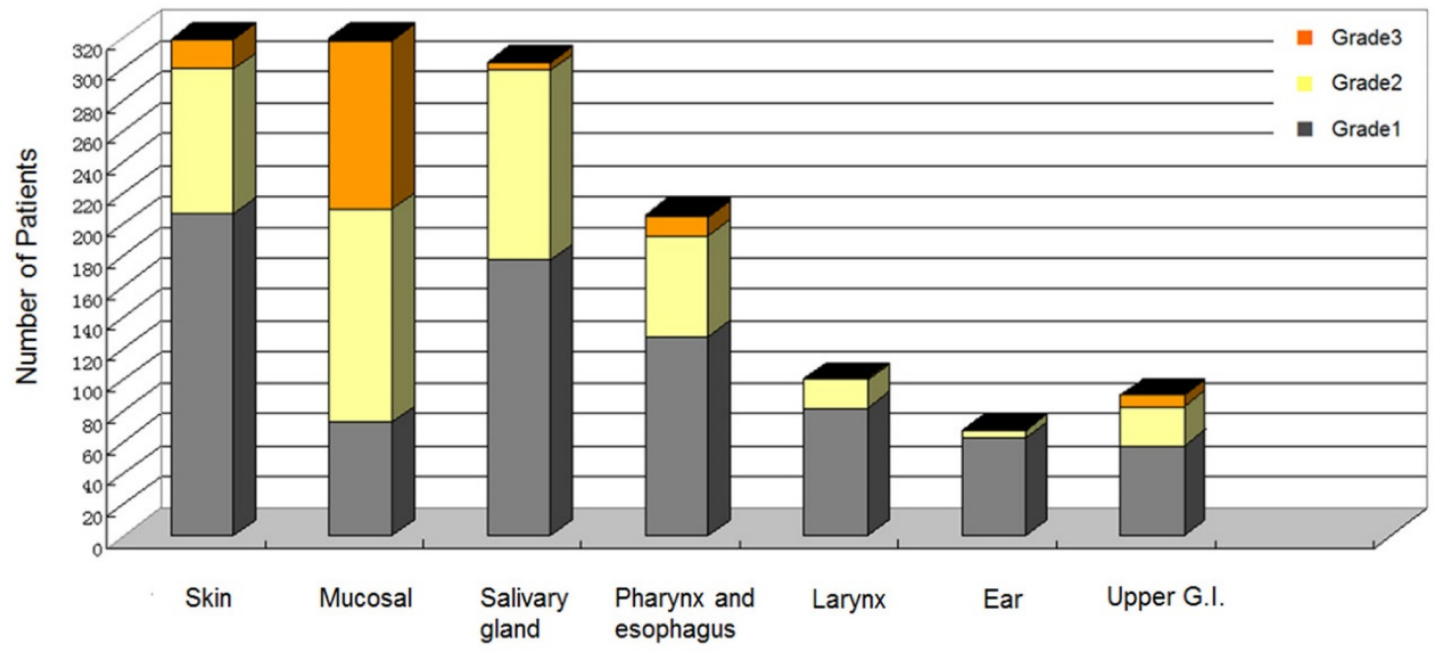

Figure 3. Acute radiation toxicities evaluation by Radiation Therapy Oncology Group criteria for 322 nasopharyngeal carcinoma patients 
Table 2. Relationships between baseline clinical factors and weight loss (\%) during radiotherapy

\begin{tabular}{|c|c|c|c|c|}
\hline \multirow[t]{2}{*}{ Baseline Factors } & \multicolumn{2}{|c|}{ Weight loss, $\%$} & \multicolumn{2}{|c|}{ correlation } \\
\hline & Mean & SD & $\mathrm{r}$ & $\mathrm{P}$ \\
\hline Gender & & & 0.036 & 0.516 \\
\hline Male & 6.9 & 4.4 & & \\
\hline Female & 6.5 & 3.9 & & \\
\hline $\begin{array}{l}\text { Age (ranged, 13-78 } \\
\text { years) }\end{array}$ & & & 0.058 & 0.299 \\
\hline$\leq 43$ years & 7.0 & 4.6 & & \\
\hline$>43$ years & 6.5 & 3.9 & & \\
\hline $\begin{array}{l}\text { UICC Tumor Stage } \\
(2010)\end{array}$ & & & 0.248 & $<0.001$ \\
\hline I & 3.5 & 3.6 & & \\
\hline II & 5.8 & 3.8 & & \\
\hline III & 7.7 & 4.0 & & \\
\hline IV & 7.3 & 4.8 & & \\
\hline Chemotherapy & & & 0.260 & $<0.001$ \\
\hline Yes $(n=221)$ & 7.6 & 4.3 & & \\
\hline No $(n=101)$ & 5.2 & 3.7 & & \\
\hline Pretreatment BMI & & & 0.096 & 0.085 \\
\hline$<18.5(\mathrm{n}=17)$ & 5.8 & 4.0 & & \\
\hline $18.5 \sim 24(n-173)$ & 6.5 & 4.2 & & \\
\hline $24 \sim 28(n=108)$ & 7.3 & 4.4 & & \\
\hline$>28(n=24)$ & 7.3 & 4.3 & & \\
\hline Pre-RT weight* & & & 0.129 & 0.021 \\
\hline$\leq 62.5 \mathrm{~kg}(\mathrm{n}=163)$ & 6.3 & 4.3 & & \\
\hline$>62.5 \mathrm{~kg}(\mathrm{n}=159)$ & 7.4 & 4.2 & & \\
\hline $\begin{array}{l}\text { Pretreatment } \\
\text { hemoglobin* }\end{array}$ & & & 0.052 & 0.348 \\
\hline$\leq 148.2 \mathrm{~g} / \mathrm{L}(\mathrm{n}=160)$ & 6.6 & 4.2 & & \\
\hline$>148.2 \mathrm{~g} / \mathrm{L}(\mathrm{n}=162)$ & 7.0 & 4.4 & & \\
\hline $\begin{array}{l}\text { Pretreatment total } \\
\text { protein* }^{*}\end{array}$ & & & 0.062 & 0.270 \\
\hline$\leq 76.8 \mathrm{~g} / \mathrm{L}(\mathrm{n}=164)$ & 6.5 & 4.4 & & \\
\hline$>76.8 \mathrm{~g} / \mathrm{L}(\mathrm{n}=158)$ & 7.1 & 4.1 & & \\
\hline Pretreatment albumin* & & & 0.112 & 0.045 \\
\hline$\leq 46 \mathrm{~g} / \mathrm{L}(\mathrm{n}=164)$ & 7.3 & 4.2 & & \\
\hline$>46 \mathrm{~g} / \mathrm{L}(\mathrm{n}=158)$ & 6.3 & 4.4 & & \\
\hline
\end{tabular}

* Variables were categorized according to the median.

Abbreviations: SD = standard deviation; $r$ = Pearson's correlation coefficient; UICC

$=$ Union for International Cancer Control; RT = radiotherapy.

Table 3. Correlations between weight loss (\%) and acute radiation toxicities during radiotherapy

\begin{tabular}{|c|c|c|c|c|c|c|c|}
\hline \multirow[t]{2}{*}{ Organ Tissue } & \multicolumn{5}{|c|}{ Grade* } & \multicolumn{2}{|c|}{ Correlation } \\
\hline & 0 & 1 & 2 & 3 & 4 & $\mathrm{r}$ & $\mathrm{P}$ \\
\hline Skin & 3 & 207 & 93 & 19 & 0 & 0.185 & 0.001 \\
\hline Mucosal & 2 & 73 & 137 & 108 & 2 & 0.273 & $<0.001$ \\
\hline Salivary gland & 18 & 177 & 122 & 5 & 0 & 0.104 & 0.063 \\
\hline $\begin{array}{l}\text { Pharynx and } \\
\text { esophagus }\end{array}$ & 116 & 128 & 65 & 12 & 1 & 0.298 & $<0.001$ \\
\hline Larynx & 221 & 82 & 18 & 1 & 0 & 0.100 & 0.072 \\
\hline Ear & 254 & 63 & 5 & 0 & 0 & 0.041 & 0.463 \\
\hline Upper G.I. & 232 & 58 & 25 & 7 & 0 & 0.165 & 0.003 \\
\hline $\begin{array}{l}\text { Grade*: Evaluat } \\
\text { (RTOG) Acute } \mathrm{R} \\
\text { Abbreviations: }\end{array}$ & by & s co & atic & $\begin{array}{l}\text { e Ra } \\
\text { ig C } \\
\text { effi }\end{array}$ & & On & Group \\
\hline
\end{tabular}

\section{Discussion}

The population of 322 NPC patients had a satisfied long-term prognosis, with 5-year OS rates $84 \%$ and 5 -year LRFS rates $93 \%$, the result was better than the data from the NPC patients receiving

conventional radiotherapy or 3-dimensional conformal radiation therapy (3DCRT) [21-23]. Consistent with the results of we reported before, the mean weight loss $(\mathrm{kg})$ was $4.0 \mathrm{~kg}$, and the mean value and median value of weight loss (\%) were $6.85 \%$ and $6.70 \%$ in these patients receiving IMRT $[12,13]$. In the survival analysis, we defined critical weight loss as body weight loss of $>5.4 \%$, based on the result of ROC analysis for mortality. Patients with critical weight loss had poorer OS and DMFS than those patients without critical weight loss. As we know, a critical weight loss during IMRT, which involving a great quantity of nutrition deletion in a short time, was reported to be correlated with metabolic abnormalities, increased risk of infections, reduction of treatment tolerance, and early mortality [24,25]. On the other hand, according to the newest definition of cancer cachexia, which defined cachexia as weight loss greater than $5 \%$, or weight loss greater than $2 \%$ in individuals already showing depletion according to current bodyweight and height (body-mass index $\left.[\mathrm{BMI}]<20 \mathrm{~kg} / \mathrm{m}^{2}\right)$ or skeletal muscle mass (sarcopenia) [26], $225(70.0 \%)$ patients in our study had cancer cachexia during their IMRT course. To best of our knowledge, cancer cachexia was related to malnutrition and a number of clinical consequences, including decreased response to treatment, increased treatment toxicity, and deteriorated quality of life [27-29]. Therefore, we should pay more attention to the commonly observed but frequently undervalued weight loss during radiotherapy for NPC patient.

Table 4. Multiple linear regression analysis using weight loss (\%) during radiotherapy as a dependent variable

\begin{tabular}{|c|c|c|c|c|c|}
\hline \multirow{2}{*}{\multicolumn{2}{|c|}{ Factors }} & \multicolumn{4}{|c|}{ Multiple linear regression } \\
\hline & & $\beta$ & SE & $95 \% \mathrm{CI}$ & $\mathrm{P}$ \\
\hline \multirow{9}{*}{$\begin{array}{l}\stackrel{\vartheta}{0} \\
\text { थे } \\
\text { के }\end{array}$} & $\begin{array}{l}\text { UICC Tumor Stage(2010) (III,IV } \\
\text { vs. I,II) }\end{array}$ & 0.541 & 0.396 & $-0.238-1.320$ & 0.173 \\
\hline & $\begin{array}{l}\text { Pre-RT weight }(\leq 62.5 \mathrm{~kg} \text { vs. } \\
>62.5 \mathrm{~kg})\end{array}$ & 1.278 & 0.447 & $0.398-2.158$ & 0.005 \\
\hline & $\begin{array}{l}\text { Pretreatment albumin }(\leq 46 \mathrm{~g} / \mathrm{L} \text { vs. } \\
>46 \mathrm{~g} / \mathrm{L})\end{array}$ & 0.519 & 0.491 & $-0.447-1.486$ & 0.291 \\
\hline & Chemotherapy (yes vs. no) & 0.919 & 0.723 & $-0.503-2.342$ & 0.205 \\
\hline & RTOG-Skin & 0.530 & 0.373 & $-0.204-1.264$ & 0.156 \\
\hline & RTOG-Mucosal & 0.883 & 0.304 & $0.285-1.482$ & 0.004 \\
\hline & RTOG-Pharynx and Esophagus & 0.995 & 0.270 & $0.464-1.525$ & $<0.001$ \\
\hline & RTOG-Upper G.I. & 0.588 & 0.284 & $0.030-1.146$ & 0.039 \\
\hline & Adjust $\mathrm{R}^{2 *}$ & 0.21 & & & \\
\hline \multirow{5}{*}{ 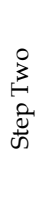 } & $\begin{array}{l}\text { Pre-RT weight }(\leq 62.5 \mathrm{~kg} \text { vs. } \\
>62.5 \mathrm{~kg})\end{array}$ & 1.183 & 0.454 & $0.290-2.077$ & 0.01 \\
\hline & RTOG-Mucosal & 1.123 & 0.304 & $0.526-1.720$ & $<0.001$ \\
\hline & RTOG-Pharynx and Esophagus & 1.085 & 0.274 & $0.546-1.624$ & $<0.001$ \\
\hline & RTOG-Upper G.I. & 0.749 & 0.285 & $0.189-1.310$ & 0.009 \\
\hline & Adjust $\mathrm{R}^{2 *}$ & 0.16 & & & \\
\hline \multicolumn{6}{|c|}{$\begin{array}{l}\text { Abbreviations: } \mathrm{SE}=\text { standard error; } \mathrm{CI}=\text { confidence interval; } \mathrm{UICC}=\text { Union for } \\
\text { International Cancer Control; RT=radiotherapy; RTOG = Radiation Therapy } \\
\text { Oncology Group. }\end{array}$} \\
\hline \multicolumn{6}{|c|}{$\begin{array}{l}\text { * The model explained } 21 \% \text { of the variance in weight loss (\%) during radiotherapy. } \\
{ }^{*} \text { The model explained } 16 \% \text { of the variance in weight loss (\%) during radiotherapy. }\end{array}$} \\
\hline
\end{tabular}


The causes of weight loss during radiotherapy were widely explored in both our previous studies and the others' studies. Lønbro et al. had reported that pretreatment BMI and tumor stage could predict critical weight loss during radiotherapy for head and neck patients [30]. Zhao et al. had reviewed twenty-two studies involving 6159 head and neck patients and found 3 predictors for weight loss: advanced tumor stage, a higher pretreatment BMI, and the use of concurrent chemoradiotherapy [31]. However, none of these previous studies had investigated the influence of acute radiation toxicities on weight loss, which refers to oral mucositis, swallowing disorders, xerostomia and so on [32]. As a result, to fully investigate the influence factors for weight loss, we had collected both the patients' general clinical characteristics and their acute radiation toxicities information. Our final multivariate analysis had showed that pre-RT weight, acute mucosal toxicity, acute pharynx and esophagus toxicity, and acute upper gastrointestinal toxicity had significant and independent impact on weight loss during IMRT. As far as we know, this study is the first systematic report about the influence of acute radiation toxicities on weight loss for NPC patients.

Based on these results, we should mainly attribute the NPC patients' weight loss during IMRT to acute radiation toxicities. The underlying connections between acute radiation toxicities and weight loss might be explained as follows: firstly, radiotherapy-induced mucositis of oral, pharynx and esophagus may result in dysphagia as well as loss of appetite, which would lead to a reduced food intake and consequently a critical weight loss [33-35]; secondly, nausea and vomiting symptom of upper gastrointestinal in NPC patients receiving concomitant chemoradiotherapy may also aggravate the weight loss [36,37]; thirdly, weight loss during radiotherapy and followed malnutrition may weaken the repair ability of radiation injury, which would cause an even serious acute injury [38]. Above all, acute radiation toxicities and weight loss aggravate each other during the whole radiotherapy process, which would finally lead to poor prognosis for NPC patients. As a result, we consider the mutual influence between acute radiation toxicities and weight loss as a "vicious circle". These correlations found in this study also prompted us to break this vicious circle. CAMPOS et al. considered oral mucositis as the most important acute side effect in head and neck patients undergoing radiotherapy and suggested that early anti-inflammatory management should be given to minimize oral mucositis and improve patients' nutritional status and quality of life [39]. Luo et al. found that a good oral hygiene status, using antibiotic at early stage, and giving up smoking were helpful to prevent severe mucositis for NPC patients [40]. Early nutritional support was also recommended to reduce weight loss and treatment-related toxicity [41-44]. As a result, these efficient measures relieving acute radiation toxicities may help to reduce the weight loss during radiotherapy. Prospective studies on how to break the vicious circle of acute radiation toxicities and weight loss are needed in the future to achieve a better prognosis for NPC.

\section{Competing Interests}

The authors have declared that no competing interest exists.

\section{References}

1. Wei WI and Sham JS. Nasopharyngeal carcinoma. Lancet. 2005; 365: 2041-2054.

2. Li G, Gao J, Liu ZG, et al. Influence of pretreatment ideal body weight percentile and albumin on prognosis of nasopharyngeal carcinoma: Long-term outcomes of 512 patients from a single institution. Head Neck. 2014; 36: 660-666.

3. Wong FC, Ng AW, Lee VH, et al. Whole-field simultaneous integrated-boost intensity-modulated radiotherapy for patients with nasopharyngeal carcinoma. Int J Radiat Oncol Biol Phys. 2010; 76: 138-145.

4. Lee N, Xia P, Quivey JM, et al. Intensity-modulated radiotherapy in the treatment of nasopharyngeal carcinoma: an update of the UCSF experience. Int J Radiat Oncol Biol Phys. 2002; 53: 12-22.

5. Tham IW, Lin S, Pan J, Han L, Lu JJ, Wee J. Intensity-modulated radiation therapy without concurrent chemotherapy for stage IIb nasopharyngeal cancer. Am J Clin Oncol. 2010; 33: 294-299.

6. Lee N, Harris J, Garden AS, et al. Intensity-modulated radiation therapy with or without chemotherapy for nasopharyngeal carcinoma: radiation therapy oncology group phase II trial 0225. J Clin Oncol. 2009; 27: 3684-3690.

7. Qiu C, Yang N, Tian G, Liu H. Weight loss during radiotherapy for nasopharyngeal carcinoma: a prospective study from northern China. Nutr Cancer. 2011; 63: 873-879.

8. Hill A, Kiss N, Hodgson B, Crowe TC, Walsh AD. Associations between nutritional status, weight loss, radiotherapy treatment toxicity and treatment outcomes in gastrointestinal cancer patients. Clin Nutr. 2011; 30: 92-98.

9. Head BA, Heitz L, Keeney C, et al. The relationship between weight loss and health-related quality of life in persons treated for head and neck cancer. Support Care Cancer. 2011; 19: 1511-1518.

10. van Wayenburg CA, Rasmussen-Conrad EL, van den Berg MG, et al. Weight loss in head and neck cancer patients little noticed in general practice. J Prim Health Care. 2010; 2: 16-21.

11. Petruson KM, Silander EM, Hammerlid EB. Quality of life as predictor of weight loss in patients with head and neck cancer. Head Neck. 2005; 27: 302-310.

12. Shen LJ, Chen C, Li BF, Gao J, Xia YF. High weight loss during radiation treatment changes the prognosis in under-/normal weight nasopharyngeal carcinoma patients for the worse: a retrospective analysis of 2433 cases. PloS One. 2013; 8: e68660.

13. Zeng Q, Shen LJ, Guo X, Guo XM, Qian CN, Wu PH. Critical weight loss predicts poor prognosis in nasopharyngeal carcinoma. BMC Cancer. 2016;16:169.

14. Du XI, Tang LL, Mao YP, et al. Value of the prognostic nutritional index and weight loss in predicting metastasis and long-term mortality in nasopharyngeal carcinoma. J Transl Med. 2015; 13: 364.

15. Trotti A Bellm LA, Epstein JB, et al Mucositis incidence, severity and associated outcomes in patients with head and neck cancer receiving radiotherapy with or without chemotherapy: a systematic literature review. Radiother Oncol. 2003; 66: 253-262.

16. Wu SX, Cui TT, Zhao $\mathrm{C}$, et al. A prospective, randomized, multi-center trial to investigate Actovegin in prevention and treatment of acute oral mucositis caused by chemoradiotherapy for nasopharyngeal carcinoma. Radiother Oncol. 2010; 97: 113-118.

17. Luo DH, Hong MH, Guo L, Cao KJ, Deng MQ, Mo HY. Analysis of oral mucositis risk factors during radiotherapy for nasopharyngeal carcinoma patients and establishment of a discriminant model. Ai Zheng. 2005; 24: 850-854.

18. Nishioka $\mathrm{T}$, Shirato $\mathrm{H}$, Arimoto $\mathrm{T}$, et al. Reduction of radiation-induced xerostomia in nasopharyngeal carcinoma using CT simulation with laser patient marking and three-field irradiation technique. Int J Radiat Oncol Biol Phys. 1997; 38: 705-712. 
19. Cox JD, Stetz J, Pajak TF. Toxicity criteria of the Radiation Therapy Oncology Group (RTOG) and the European Organization for Research and Treatment of Cancer (EORTC). Int J Radiat Oncol Biol Phys. 1995; 31: 1341-1346.

20. Greiner M, Pfeiffer D, Smith RD. Principles and practical application of the receiver-operating characteristic analysis for diagnostic tests. Prev Vet Med. 2000; 45: 23-41.

21. Hsiung $\mathrm{CY}$, Ting $\mathrm{HM}$, Huang $\mathrm{HY}$, Lee $\mathrm{CH}$, Huang $\mathrm{EY}$, Hsu $\mathrm{HC}$ Parotid-sparing intensity-modulated radiotherapy (IMRT) for nasopharyngeal carcinoma: preserved parotid function after IMRT on quantitative salivary scintigraphy, and comparison with historical data after conventional radiotherapy. Int J Radiat Oncol Biol Phys. 2006;66:454-461.

22. Zhang Y, Lin ZA, Pan JJ, Zheng Z, Yang L, Lin SJ, et al. Concurrent control study of different radiotherapy for primary nasopharyngeal carcinoma: intensity-modulated radiotherapy versus conventional radiotherapy. $\mathrm{Ai}$ Zheng. 2009; 28: 1143-1148.

23. Cheng JC, Chao KS, Low D. Comparison of intensity modulated radiation therapy (IMRT) treatment techniques for nasopharyngeal carcinoma. Int J Cancer. 2001; 96: 126-131.

24. Lin A, Jabbari S, Worden FP, et al. Metabolic abnormalities associated with weight loss during chemoirradiation of head-and-neck cancer. Int J Radiat Oncol Biol Phys. 2005; 63: 1413-1418.

25. Nguyen TV, Yueh B. Weight loss predicts mortality after recurrent oral cavity and oropharyngeal carcinomas. Cancer. 2002; 95: 553-562.

26. Fearon K, Strasser F, Anker SD, et al. Definition and classification of cancer cachexia: an international consensus. Lancet Oncol. 2011; 12: 489-495.

27. Mariani L, Lo VS, Bozzetti F. Weight loss in cancer patients: a plea for a better awareness of the issue. Support Care Cancer. 2012; 20: 301-309.

28. Hill A, Kiss N, Hodgson B, Crowe TC, Walsh AD. Associations between nutritional status, weight loss, radiotherapy treatment toxicity and treatment outcomes in gastrointestinal cancer patients. Clin Nutr. 2011; 30: 92-98.

29. Hart PA, Kamada P, Rabe KG, et al. Weight loss precedes cancer-specific symptoms in pancreatic cancer-associated diabetes mellitus. Pancreas. 2011; 40: 768-772.

30. Lonbro S, Petersen GB, Andersen JR, Johansen J. Prediction of critical weight loss during radiation treatment in head and neck cancer patients is dependent on BMI. Support Care Cancer. 2016; 24: 2101-2109.

31. Zhao JZ, Zheng H, Li LY, Zhang LY, Zhao Y, Jiang N. Predictors for Weight Loss in Head and Neck Cancer Patients Undergoing Radiotherapy: A Systematic Review. Cancer Nurs. 2015; 38: E37-45.

32. Meyer F, Fortin A, Wang CS, Liu G, Bairati I. Predictors of Severe Acute and Late Toxicities in Patients With Localized Head-and-Neck Cancer Treated With Radiation Therapy. Int J Radiat Oncol Biol Phys. 2012; 82: 1454-1462.

33. Patni N, Patni S, Bapna A. The optimal use of granulocyte macrophage colony stimulating factor in radiation induced mucositis in head and neck squamous cell carcinoma. J Cancer Res Ther. 2005; 1: 136-141.

34. Lin PH, Hsiao TY, Chang YC, et al. Effects of functional electrical stimulation on dysphagia caused by radiation therapy in patients with nasopharyngeal carcinoma. Support Care Cancer. 2011; 19: 91-99.

35. Lovell SJ, Wong HB, Loh KS, Ngo RY, Wilson JA. Impact of dysphagia on quality-of-life in nasopharyngeal carcinoma. Head Neck. 2005; 27: 864-872.

36. Skarlos DV, Fountzilas G, Pavlidis N, et al. Megestrol acetate in cancer patients with anorexia and weight loss. A Hellenic Co-operative Oncology Group (HeCOG) study. Acta Oncol. 1993; 32: 37-41.

37. Enblom A, Bergius AB, Steineck G, Hammar M, Borjeson S. One third of patients with radiotherapy-induced nausea consider their antiemetic treatment insufficient. Support Care Cancer. 2009; 17: 23-32.

38. YOUMANS JB. Nutrition; maintenance, function, and repair. Oral Surg Oral Med Oral Pathol. 1948; 1: 184-198.

39. Campos MI, Campos CN, Aarestrup FM, Aarestrup BJ. Oral mucositis in cancer treatment: Natural history, prevention and treatment. Mol Clin Oncol. 2014; 2 : 337-340.

40. Luo DH, Hong MH, Guo L, Cao KJ, Deng MQ, Mo HY. Analysis of oral mucositis risk factors during radiotherapy for nasopharyngeal carcinoma patients and establishment of a discriminant model. Ai Zheng. 2005; 24: 850-854.

41. Tozer RG, Tai P, Falconer W, et al. Cysteine-rich protein reverses weight loss in lung cancer patients receiving chemotherapy or radiotherapy. Antioxid Redox Signal. 2008; 10: 395-402.

42. van den Berg MG, Rasmussen-Conrad EL, Wei KH, Lintz-Luidens $\mathrm{H}$, Kaanders JH, Merkx MA. Comparison of the effect of individual dietary counselling and of standard nutritional care on weight loss in patients with head and neck cancer undergoing radiotherapy. Br J Nutr. 2010; 104: 872-877.

43. Lee H, Havrila C, Bravo V, et al. Effect of oral nutritional supplementation on weight loss and percutaneous endoscopic gastrostomy tube rates in patients treated with radiotherapy for oropharyngeal carcinoma. Support Care Cancer. 2008; 16: 285-289.

44. Wiggenraad RG, Flierman L, Goossens A, et al. Prophylactic gastrostomy placement and early tube feeding may limit loss of weight during chemoradiotherapy for advanced head and neck cancer, a preliminary study. Clin Otolaryngol. 2007; 32: 384-390. 